\title{
Investigation of Shear Properties of Coral Sands
}

\author{
Binbin $\mathrm{Xu}^{1, \mathrm{a}}$ and $\mathrm{Wei} \mathrm{Si}^{2, \mathrm{~b}}$ \\ ${ }^{1}$ Tianjin Port Engineering Institute Ltd. of CCCC, Tianjin, China; Key Lab. of Geotechnical \\ Engineering of Tianjin, Tianjin, China; Key Lab. of Geotechnical Engineering, Ministry of \\ Communication, Tianjin, China \\ 2 Tianjin Port Engineering Institute Ltd. of CCCC, Tianjin, China \\ axubinbin@tpei.com.cn, bsiwei@tpei.com.cn
}

\begin{abstract}
Keywords: Coral sand, Drained shear, Undrained shear, Shear behavior, Critical state
Abstract. When the quite different physical properties of coral sand from the land sand is found, many researcher have devoted themselves to investigating its mechanical properties. It is generally believed that there are many influence factors including content of carbonate, relative density, stress history, cement degree, particle breakage of the shear strength of the coral sand. This paper reviewed the previous shear results of coral sand summarized some common properties of coral sand in different locations. The drained and undrained triaxial shear test results were also shown to help understand the special shear properties of the coral sand.
\end{abstract}

\section{Introduction}

The coral sand is usually rich in calcium carbonate or other indissolvable calcium salt and it belongs to marine sediments. In the tropical areas including China, Japan, India, Australia, American, it is widely distributed. Because there is no long-distance transport during the sedimentation of coral sand, it keeps the tiny void inside the particle which makes the engineering properties quite different from the ordinary marine sedimentations.

According to previous researches, the coral sand has high void ratio between 0.7 and 2.5 , while the ordinary siliceous sand is between 0.4 and 0.9 . And also the stiffness of coral particles is very low, all of which makes the shear properties of coral sand much different from other land sands. In order to summarize the detailed shear properties of coral sand, the literature review is carried out using previous experimental results to instruct the following construction and design.

\section{Current Research}

The first time that the coral sand appear in the research literature is in 1960. During the construction of Lavan oil platform, a pile with $1 \mathrm{~m}$ diameters suddenly dropped around $15 \mathrm{~m}$ after going through a $8 \mathrm{~m}$ well-cementation ground and the much difference between coral sand and siliceous sand began to be realized. Then, in the construction of pile foundation of oil platform at North Rankin, the researcher finally realized that the coral sand is a new type of soil and the conventional method is no longer suitable for such kind of soil.

The North Rankin's oil platform set off a rush in the research of coral sand. Coop's results[1] shows that there is a tendency to constant volume and constant deviator stress during the drained triaxial compression tests, which is quite similar to the clay. When the effective confining pressure increases, the initial state of the coral state becomes normally consolidated from overconsolidated state. If the confining pressure is large enough, the finial stress ratio of each test may be the same. Fahey[2] believed that the drained shear behavior is quite different at high confining pressure and low confining pressure respectively. When the confining pressure is relatively low, the initial response is rigid and after that there is a yield point and then goes into the hardening stage. While for the high confining pressure, the initial response is a bit weak and there is no obvious yield point.

In the undrained triaxial compression test, the pore pressure increases and the mean effective stress decrease due to the rearrangement of particle grains for the siliceous sand. After that, the negative pore pressure occurs due to dilatancy and the mean effective stress increases which makes 
the stress path towards the critical state. However, for the coral sand the positive pore pressure occurs at the initial stages of shear and the mean effective stress decreases. When reaching the peak of deviator stress, the pore pressure decreases a little and the mean effective stress increases, together with the close of stress path and critical state. Generally speaking, the effective inner friction angle of coral sand is much greater than that of most siliceous sand, and the envelope line of coral sand is usually non-linear. The shear strength of the coral sand is influenced by the content of carbonate, relative density, stress history, cement degree, particle breakage and so on. Next, some experimental results are shown to emphasis the above shear characteristics of coral sand.

\section{Shear Properties}

The triaxial undrain shear tests of coral sand in Goodwyn [3] and Toyoura siliceous sand [4] are shown in Figure 1. Two sands have the similar initial relative density about $60 \%$. For another example, the undrained shear test of coral sand in Dogs Bay and siliceous sand in Leighton Buzzard $[1,5]$ are presented in Figure 2. From the figures, it is revealed that sands with similar relative density demonstrate totally different behaviors. There is significant dilative behavior for the siliceous sands while volumetric compression due to dilatancy can be found in the coral sand, which can be ascribed to the particle breakage.

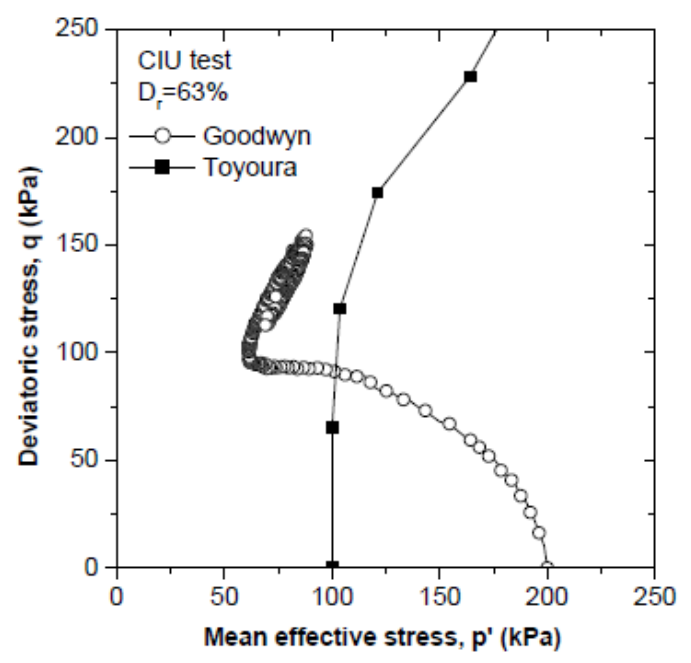

(a)

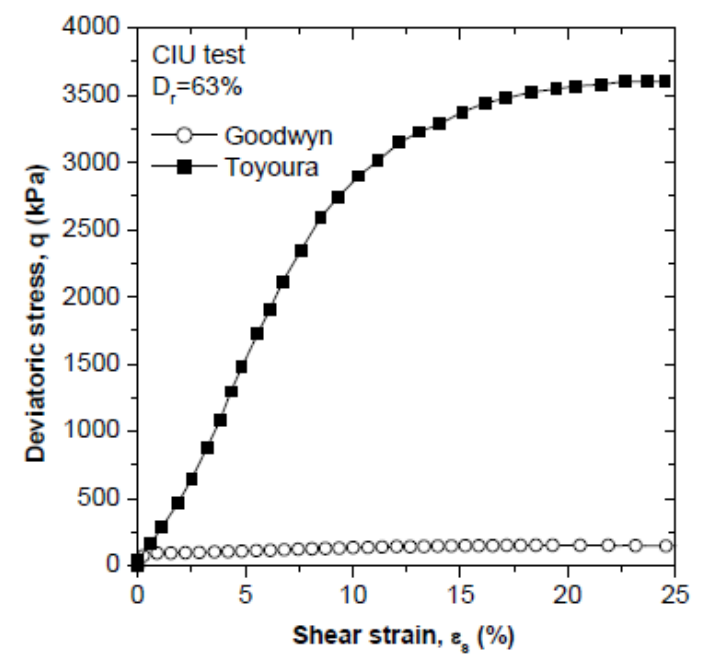

(b)

Figure 1 Triaxial undrained shear tests for Goodwyn coral (after Ishihara, 1993)

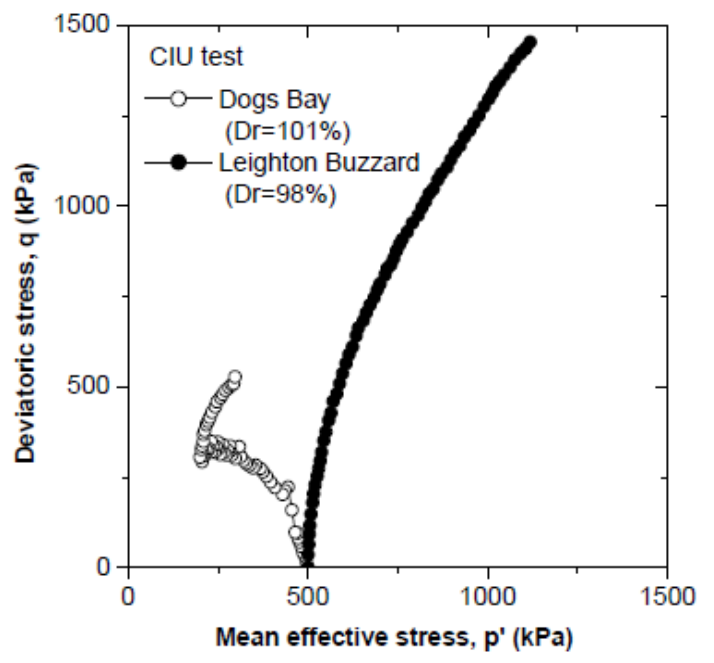

(a)

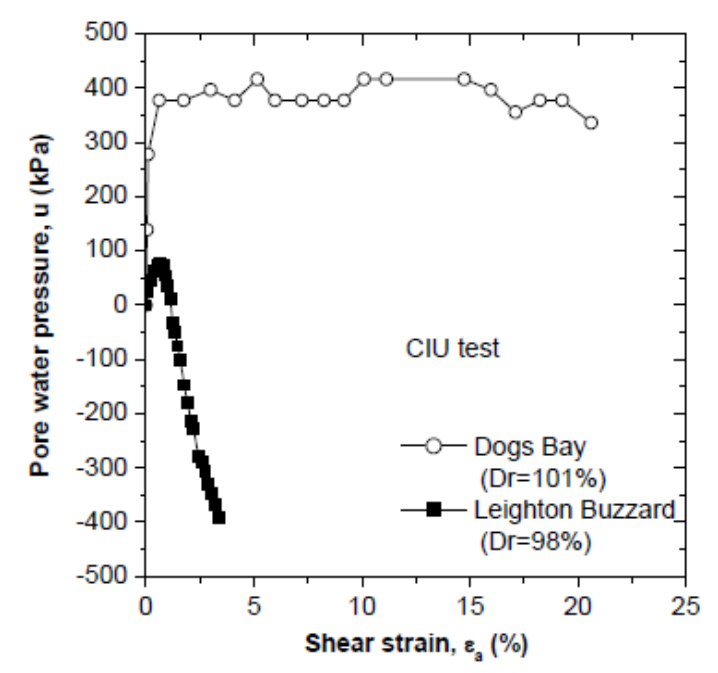

(b)

Figure 2 Triaxial undrained shear tests for Dogs Bay coral and Leighton Buzzard siliceous sands (after Coop 1990 and Golightly 1988) 
If the siliceous sand is in a very loose state, the particles will form an assemblage where the contact and gaps can be seen between the particles. When the external shear stress is applied, the contact among the inner particles become closer and the particles would fill into the gaps formed by certain particles. Furthermore, as the shear stress increases the gaps between are sufficiently filled and the density of the sand becomes larger accordingly. If the shear stress increases more, the rearrangement of the particles can be found and volumetric expansion can be seen, which is defined as dilatancy due to shear action. Similar to the overconsolidated clay, dilatancy is one of the most important properties for the sand.

However, the particles of coral sands are sensitive to the shear stress and even under moderate shear stress level, particle breakage can be found. As can be seen in Figure 1(a), after the phase transformation stage, there is a little dilative behavior in the stress path of Goodwyn sands. Then after the peak stress when the strain is relatively large, the stress path goes back to the residual state which can be called critical state. Different from the siliceous sand, although the particles of coral sand begin to be rearranged at the initial stage of shear loading, actually the particle breakage also begins to occur under the shear action and the fragments due to particle breakage would fill the gap between particles. Because of the high roughness of the coral particles, a steeper CSL can be expected for the coral sand and also results in the higher friction angle.

The evidence of different shear mechanism between siliceous sands and coral sands can also be found in the variation of pore water pressure. As can be seen from Figure 2(b), there is an obvious reduction in the pore water pressure for the dense siliceous sands and it can be ascribed to the dilatancy of the sand associated with volume expansion. While for the coral sands the pore water pressure tends to increases due to the volumetric compression. Note that the relative density of coral sand in Dogs Bay is already over $100 \%$ which implies that there has been particle breakage in the initial state due to the very high confining pressure.

The drained shear tests of coral sands and siliceous sands are shown in Figures 3 and 4 under low confining pressure $[5,6]$ and high confining pressure $[1,7]$ respectively. As can be seen, the initial stiffness of siliceous sands is much higher than that of coral sands. However, as the shear strain increases, the shear strain of coral sands is finally higher than that of siliceous sands. It can be concluded that the stiffness and strength of the coral sand increases gradually as the particle breakage occurs under high pressure. But for the siliceous sands, the shear bands, namely strain localization would occur at high strain level which results in the deduction of the deviator stress. Volumetric expansion can be found in siliceous sand while volumetric compression can be found in coral sands, as can be seen in Figure 3(b).

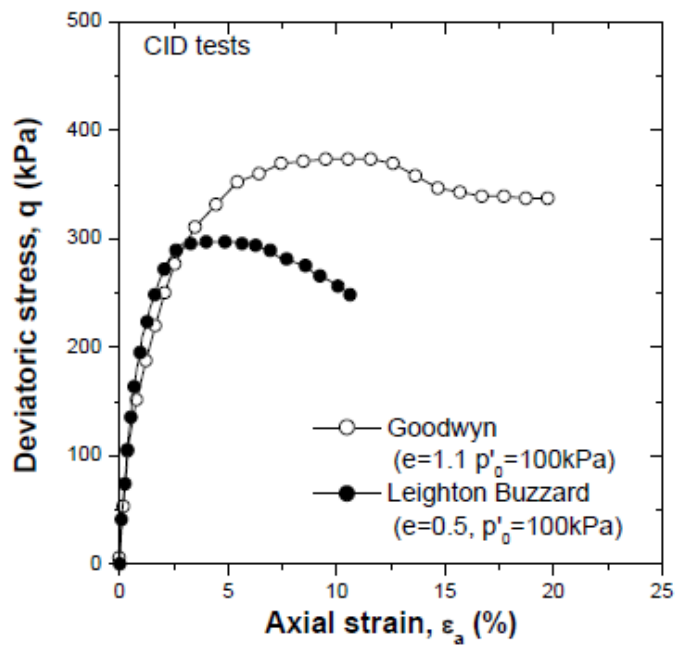

(a)

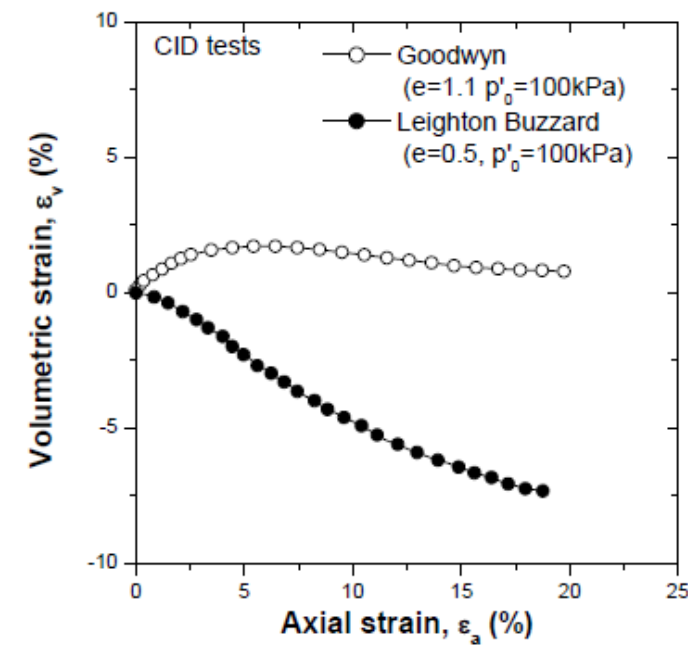

(b)

Figure 3 Low-confined triaxial drained shear tests for Goodwyn coral and Leighton Buzzard siliceous sands (after Finnie 1993 and Golight 1988) 


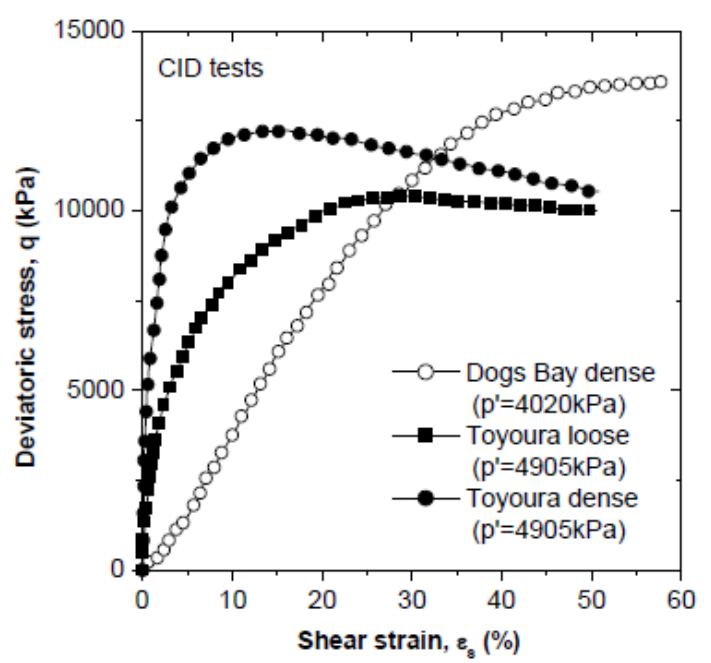

(a)

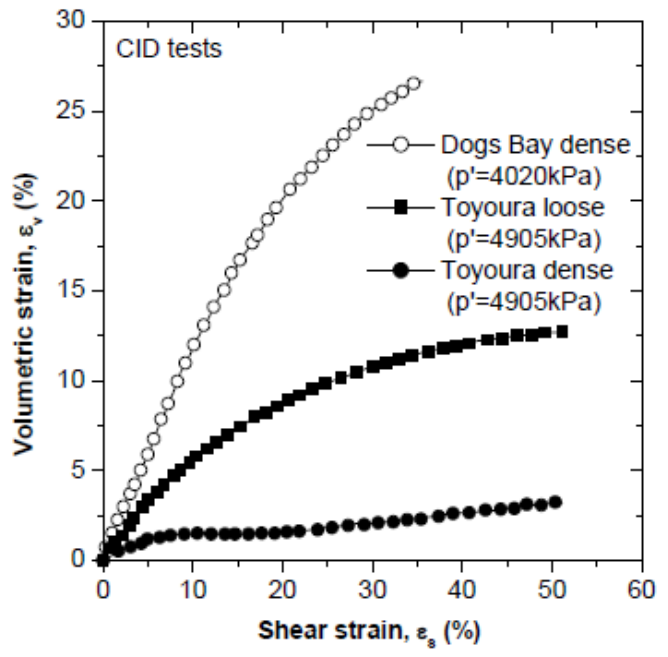

(b)

Figure 4 High-confined triaxial drained shear tests for Dogs Bay coral and Toyoura siliceous sands (after Coop 1990 and Ishihara 1993)

\section{Conclusions}

Due to the significant differences in physical properties of the coral sand, the shear characteristics of coral sand is also quite different from other land sand. In this paper, the literature review about the shear result of coral sand is carried out to summarize the basic regulation and the conclusions are as follows:

1) The shear strength of the coral sand is influenced by the content of carbonate, relative density, stress history, cement degree and particle breakage

2) During the shear loading, the strong dilatancy is found in siliceous sand while greater compressibility is found in coral sand.

3) During the drained triaxial compression tests, the response of the coral sand is quite similar to the clay. When the effective confining pressure increases, the initial state of the coral state becomes normally consolidated from overconsolidated state. If the confining pressure is large enough, the finial stress ratio of each test may be the same.

4) In the undrained triaxial compression test, the positive pore pressure occurs at the initial stages of shear and the mean effective stress decreases. When reaching the peak of deviator stress, the pore pressure decreases a little and the mean effective stress increases, together with the close of stress path and critical state.

\section{References}

[1] M.R. Coop: Geotechnique, Vol. 40-4, (1990), p. 607.

[2] M. Fahey: Jewell and Khorshided Vol. 1 (1991), p. 61.

[3] S.S.A. Sharma: PhD thesis, University of Western Australia, Australia (2004).

[4] K. Ishihara: Geotechnique, Vol 43-3, (1993), p. 351.

[5] C.R. Golight and A.F.L. Hyde: Engineering for Calcareous Sediments, Vol. 1, Perth, Australia, Balkema, Rotterdam: p.69.

[6] I.M.F. Finnie, $\mathrm{PhD}$ thesis, University of Western Australia, Australia.

[7] N. Mimura and T. Yamanouchi: Soils and Foundations, Vol. 15-4, (1975), p. 23. 